\title{
PEMETAAN DATA KRIMINALITAS DI KOTA MALANG BERBASIS WEBGIS
}

\author{
Riza Dwi Octavianti ${ }^{1}$, Nurudin Santoso ${ }^{2}$, Siti Romlah ${ }^{3}$ \\ 1,2 Jurusan Teknik Elektro, Program Studi Teknik Informatika, Politeknik Negeri Malang \\ 1' rizadwioctavianti@gmail.com, ${ }^{2}$ nurudin.santoso@gmail.com, ${ }^{3}$ sihalmor@gmail.com
}

\begin{abstract}
Abstrak
Sebagai kota pendidikan dan pariwisata, Kota Malang setiap tahun pertumbuhan penduduknya semakin pesat. Hal ini menyebabkan terbatasnya lapangan pekerjaan yang berdampak pada meningkatnya tindakan kriminal. Oleh karena itu, masyarakat perlu meningkatkan kewaspadaan terhadap tindak kriminal yang bisa terjadi dimana saja. Terbatasnya informasi mengenai daerah yang rawan dengan tindakan kriminal menjadi salah satu faktor yang perlu diperhatikan oleh pihak kepolisian Kota Malang dan masyarakat. Sistem Informasi Geografis merupakan salah satu alternatif yang dapat diberikan oleh pihak kepolisian kepada masyarakat Kota Malang untuk memberikan informasi tentang daerah yang rawan tindakan kriminal. Karena itulah dibuat aplikasi Pemetaan Data Kriminalitas Di Kota Malang Berbasis WEBGIS untuk memberikan informasi tentang persebaran titik kriminalitas, pemetaan dan statistik kriminalitas di Kota Malang. Sistem ini mengintegrasikan teknik pengelolaan data spasial untuk pemrograman berbasis web. Bahasa pemrograman yang digunakan untuk membangun halaman web adalah $P H P$, HTML, dan Javascript. Konfigurasi peta menggunakan fasilitas API dari Google Maps. Sedangakan pengelolahan basisdata menggunakan MySQL. Aplikasi ini dapat memberikan informasi persebaran titik-titik kriminalitas dalam peta berbasis web dengan ikon yang berbeda. Selain itu, aplikasi ini dapat menampilkan pemetaan kriminalitas dengan warna yang berbeda sesuai dengan banyaknya jumlah kejahatan yang terjadi serta aplikasi ini dapat menampilkan statistik kriminalitas setiap kecamatan selama satu tahun.
\end{abstract}

Kata kunci: Sistem Informasi Geografis, Kriminal, Pemetetaan Kota Malang

\section{Pendahuluan}

Kota Malang yang terletak pada ketinggian antara 440 - 667 meter diatas permukaan air laut, merupakan salah satu kota di Jawa Timur. Tingkat pertumbuhan penduduk Kota Malang sampai tahun 2013 sebesar 845.683 jiwa. Kepadatan penduduk kurang lebih 7.453 jiwa per kilometer persegi. Tersebar di 5 Kecamatan (Klojen = 107.753 jiwa, Blimbing $=186.831$ jiwa, Kedungkandang $=193.868$ jiwa, Sukun $=$ 193.384 jiwa, dan Lowokwaru $=162.771$ jiwa). Terdiri dari 57 Kelurahan, 536 unit RW dan 4.011 unit RT. (sumber : http://dispendukcapil.malangkota.go.id/ )

Pertumbuhan penduduk Kota Malang semakin tahun semakin pesat dikarenakan Kota Malang mendapat julukan sebagai kota pendidikan dan pariwisata Seiiring dengan bertambahnya kepadatan penduduk di Kota Malang membuat terbatasnya lapangan pekerjaan yang berdampak pada meningkatnya tindakan kriminal.

Menurut Kartono (1991) dalam Christian Y. Lumenta, John S. Kekenusa, Djoni Hatidja(2012) kriminalitas atau tindak kejahatan adalah tingkah laku yang melanggar hukum dan melanggar normanorma sosial, sehingga masyarakat menentangnya.

Kasus kriminalitas yang sering terjadi seperti pencurian barang berharga, pencurian kendaraan bermotor, perampasan atau penjambretan, pembunuhan, penipuan, dan lain sebagainya. Oleh karena itu, masyarakat perlu meningkatkan kewaspadaan terhadap 
tindak kriminal yang bisa terjadi dimana saja. Terbatasnya informasi mengenai daerah yang rawan dengan tindakan kriminal menjadi salah satu faktor yang perlu diperhatikan oleh pihak kepolisian Kota Malang dan masyarakat.

Sistem Informasi Geografis (SIG) atau Geographic Information System (GIS) adalah suatu alat yang berbasis komputer yang dipergunakan untuk memetakan dan menganalisis berbagai objek dan peristiwa yang terjadi di bumi.

Menurut Ahmad Mirza, Haidir Rahman, dan R. Dimas (2013) dalam Perancangan Basis Data Sistem Informasi Geografi Titik Rawan Kriminal Di Jakarta, informasi geografis yang berkaitan dengan informasi dan persebaran titik rawan kriminal di wilayah DKI Jakarta agar dapat mengetahui wilayah potensial yang sering terjadi tindak kriminal. Selain itu informasi yang didapat antara lain mengetahui tingginya tingkat kriminal pada daerah tersebut, kemudian mengetahui dan menentukan status aman, siaga dan sigap pada wilayah tersebut.

Dengan uraian di atas, penulis tertarik untuk melakukan penelitian dengan judul "PEMETAAN DATA KRIMINALITAS DI KOTA MALANG BERBASIS WEBGIS".

\subsection{Landasan Teori}

\subsubsection{Sistem Informasi Geografis} Menurut Aronoff, dalam Pengembangan Aplikasi Sistem Informasi Geografis Berbasis Dekstop dan Web (Riyanto dkk, 2009:36) mendefinisikan SIG sebagai sebuah sistem berbasiskan komputer yang digunakan untuk menyimpan dan memanipulasi informasi-informasi geografis. SIG dirancang untuk mengumpulkan, menyimpan, dan menganalisis objek-objek dan fenomena dimana lokasi geografi merupakan karateristik yang penting atau kritis untuk dianalisis.

\subsubsection{Google Maps}

Google Maps merupakan salah satu fasilitas dari Google yang menyediakan layanan pemetaan suatu daerah. Pemetaan tersebut dilengkapi dengan berbagai kemampuan dan mudah digunakan. Kelengkapan lain pendukung peta tersebut seperti layanan informasi bisnis, jasa, layanan public, jalan, lokasi, dan lain-lain (Febrian, 2008).
Fitur-fitur yang terdapat dalam Google Maps adalah: Integrated business search results, Dragable Maps, Satellite Imagery. Digunakan untuk melihat foto dari satelit. Detailed directions, Keyboard shortcut, dan Scroll wheel zooming. (Febrian, 2008).

\subsubsection{Google Maps API}

Dengan Google Maps API ini

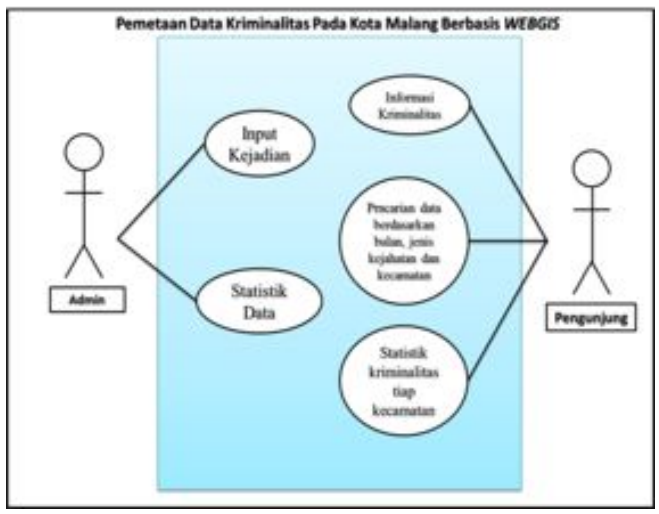

pengguna dapat membuat aplikasi $w e b$ dan seluler menarik dengan platform pemetaan canggih dari Google termasuk basis data citra satelit, pemandangan jalan, profil ketinggian, petunjuk arah mengemudi, peta dengan sentuhan gaya, demografi, analisis, dan tempat yang luas.

\section{Metode Penelitian}

a. Tahapan Penelitian

2.2.1 Metode Pencarian Fakta

a. Studi Kepustakaan

Sumber pustaka tersebut dapat berupa karya ilmiah, artikel-artikel tertulis, dan sumber-sumber lainnya yang bersangkutan dengan pembuatan skripsi ini.

\subsubsection{Pengembangan Perangkat Lunak} Metodologi pengembangan yang digunakan untuk aplikasi ini adalah Waterfall Model. Tahapannya adalah:

a. Collecting Data

Melakukan pengumpulan data di Polres Kota Malang tentang kriminalitas yang terjadi di Kota Malang dalam 12 bulan terakhir atau pada tahun 2013 dan merupakan inventaris Polres Kota Malang.

b. Analys 
Tahap ini merupakan tahap pengumpulan kebutuhan perangkat lunak dan studi kebutuhan user atau pengunjung.

c. Design System

Tahapan ini adalah tahapan untuk menentukan perangkat lunak yang digunakan dalam pembuatan sistem serta spesifikasi rancangan sistem sehingga mudah diwujudkan pada saat dibangun.

d. Programming

Tahapan ini menghasilkan hasil yang akhirnya berupa user interface sistem.

e. Testing

Bagian akhir dari pembuatan sistem, pengecekan kembali sistem, bagaimana sistem berjalan, kualitas dari sistem dan kelayakan sistem dari kebutuhan yang telah di tetapkan.

\section{f. Implementation}

Mengimplementasikan

dengan cara membuat aplikasi ini berjalan dengan mudah dipahami oleh pengunjung yang masih belum mengerti TI.

\section{b. Perancangan Sistem}

\section{i. Use Case}

Gambar 2.2 Use Case

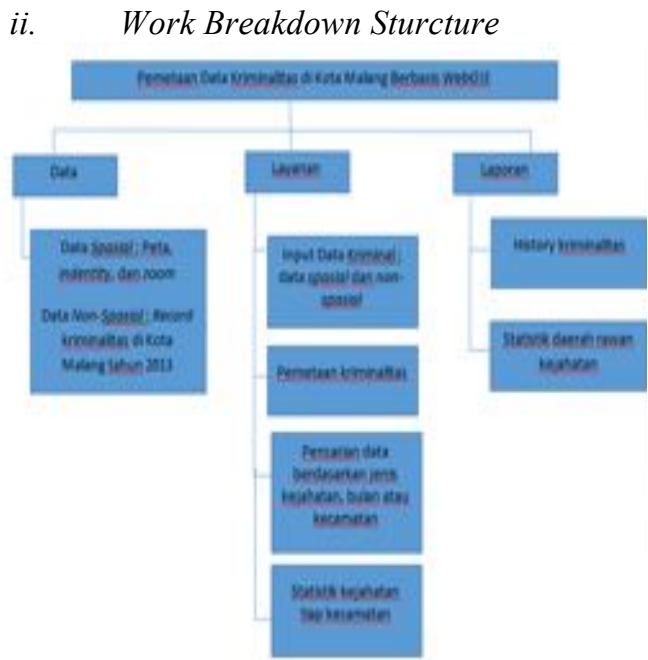

Gambar 2.3 Work Breakdown Structure

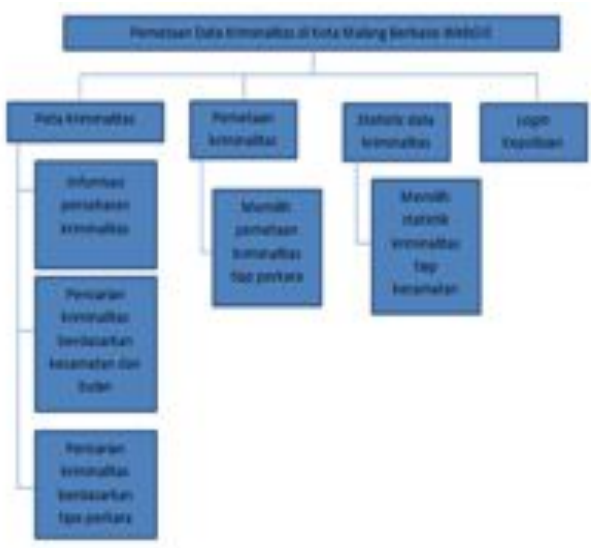

Gambar 2.4 Sitemap

\section{Hasil}

\subsection{Peta Kriminalitas}

Peta Kriminalitas merupakan informasi dari hasil penambahan data kriminalitas. Pengunjung dapat melihat informasi kriminalitas berdasarkan tipe perkara dengan cara memilih pada menu legend pada pojok kanan bawah peta. Serta pengunjung dapat melihat informasi berdasarkan kecamatan, bulan dan tahun.

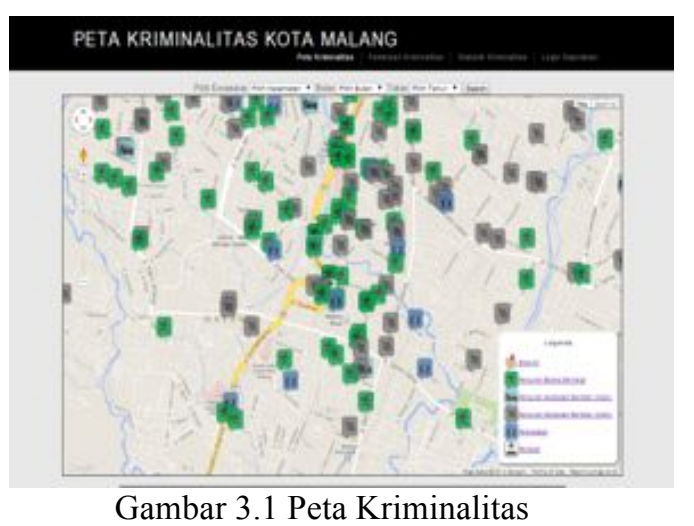

\subsection{Pemetaan Kriminalitas}

Pemetaan kriminalitas akan menampilkan 5 warna berbeda di setiap kecamatan pada Kota Malang. Warnawarna tersebut menunjukkan sering tidaknya terjadi tindak kejahatan pada kecamatan tersebut. Jika warna semakin gelap maka daerah tersebut sering terjadi tindak kejahatan selama tahun 2013. 


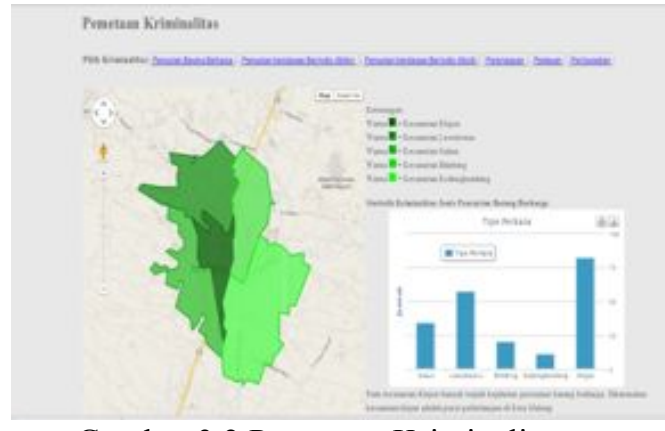

Gambar 3.2 Pemetaan Kriminalitas

\subsection{Statistik Kriminalitas}

Statistik kriminalitas akan menampilkan 5 warna berbeda di setiap kecamatan pada Kota Malang. Jika salah satu warna di-klik pada peta maka akan muncul informasi statistik kriminalitas pada kecamatan tersebut dalam tahun 2013.

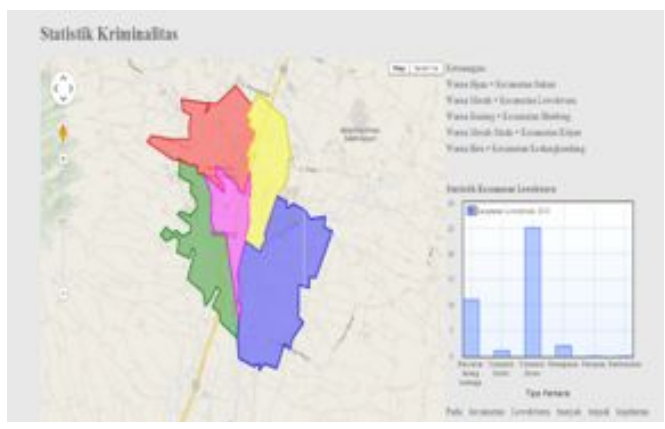

Gambar 3.3 Statistik Kriminalitas system ini adalah penanganan system yang masih ditangani oleh personel Polri (reserse), sehingga akan terhambat jika personel yang bersangkutan sedang mengadakan tugas diluar kantor.

c. Opportunities (Peluang)

Peluang yangberhasil diidentifikasi :

- Belum tersedianya system yang memberikan informasi berupa peta sebaran lokasi kejadian tindak kejahatan pada masyarakat.

- Belum ada system yang menyediakan informasi tabel dan grafik kriminalitas di Malang secara online.

Pengembangan sistem ini juga didukung oleh kondisi dan situasi di lingkungan institusi Polri serta masyarakat pada umumnya, yaitu :

- Diterbitkan UU No. 14 tahun 2008 tentang Keterbukaan Informasi Publik.

- Fasilitas dan infrastruktur penyedia informasi sudah dapat diperoleh secara mudah.

- Tersedianya perangkat komunikasi canggih dengan harga terjangkau.

- Masyarakat cenderung memiliki rasa ingin tahu yang besar terhadap informasi dan perkembangan situasi terbaru.

d. Threats (Hambatan)

Hambatan yang mungkin akan dijumpai pada saat implementasi sistem ini adalah belum adanya pemetaan secara otomatis pada sistem ini.

\section{Pembahasan SWOT \\ 4.1 Pembahasan Dengan Analisis}

Berdasarkan UU No. 14 Tahun 2008 tentang Keterbukaan Informasi Publik, system ini diharapkan dapat menyediakan informasi untuk lebih meningkatkan partisipasi masyarakat baik dalam hal pengambilan kebijakan maupun strategi kewaspadaan dan pencegahan tindak kriminal.

a. Strengths (Kekuatan)

Situasi internal Polresta Malang yang mendukung proses implementasi sistem baru ini adalah :

- Satreskim memiliki koleksi data kriminalitas berupa laporan tindak kejahatan yang lengkap, akurat, dan up to date.

b. Weakness (Kelemahan)

Kondisi internal Polresta Malang yang belum mendukung implementasi

\subsection{Analisis Kelayakan Sistem}

\subsubsection{Analisa Kelayakan Teknologi}

Sistem ini dikembangkan sebagai sistem informasi geografis berbasis web dengan memanfaatkan Google Maps API yang memiliki fitur-fitur lengkap untuk mendukung publikasi data spasial.

\subsubsection{Analisa Kelayakan Operasional \\ Sistem ini memiliki kemampuan untuk mempublikasikan data kasus kriminalitas dan persebarannya dalam peta berbasis web. Data kriminalitas sudah tersedia di Satreskim Polresta Malang, tetapi masih dalam format standar laporan kepolisian. Untuk dapat digunakan dalam sistem, data tersebut terlebih dahulu harus diolah agar sesuai dengan peruntukan konsumsi publik.}




\subsubsection{Analisa Kelayakan Hukum}

Kebebasan publik untuk mendapat informasi telah diatur dalam UU No. 14 Tahun 2008 tentang Keterbukaan Informasi Publik. Meskipun demikian, informasi yang di publikasikan tetap dibatasi pada informasi-informasi yang tidak dikecualikan. Informasi yang dikecualikan dalam undang-undang tersebut antara lain informasi terkait rahasia Negara, dan informasi yang dapat mempengaruhi jalannya proses penyelidikan atau penyidikan tindak criminal

\section{Penutup}

\subsection{Kesimpulan}

Kesimpulan yang diperoleh dari hasil Pemetaan Data Kriminalitas Di Kota Malang Berbasis WebGIS adalah :

1. Dapat memberikan informasi kriminalitas pada Kota Malang menggunakan SIG.

2. Memudahkan masyarakat dalam mengetahui persebaran, pemetaan, dan statistik kriminalitas di Kota Malang.

3. Dapat menunjukkan lokasi titik kriminal yang terjadi di Kota Malang.

\subsection{Saran}

Dalam pembuatan apilkasi ini mungkin masih terdapat kekurangan, oleh karena itu untuk kedepannya perlu diadakan pengembangan lagi agar aplikasi ini semakin menarik. maka disarankan melakukan hal-hal sebagai berikut:
1. Fitur pengelolahan data-data yang lebih dinamis pada halaman administrator dan pengunjung terutama fitur pemetaan.

2. Perlu pengembangan lagi fungsi-fungsi maupun pemrograman yang ada agar dapat dikembangkan ke aplikasi yang lebih luas..

\section{Daftar Pustaka}

Ahmad Mirza, Haidir Rahman, dan R. Dimas. 2013. Perancangan Basis Data Sistem Informasi Geografi Titik Rawan Kriminal Di Jakarta.

Christian Y. Lumenta, John S. Kekenusa, dan Djoni Hatidja. 2012. ANALISIS JALUR FAKTOR-FAKTOR PENYEBAB KRIMINALITAS DI KOTA MANADO, Jurnal Ilmiah Sains Vol. 12 No. 2.

Febrian, J. , 2008. Menjelajah Dunia dengan Google, Mesin Pencarian Informasi di Internet Terbesar di Dunia, Penerbit Informatika, Bandung.

Raharjo, B. 2011. Belajar Otodidak Pemrograman Web dengan PHP + Oracle, Bandung. Informatika.

Riyanto, dkk. 2009. Pengembangan Aplikasi Sistem Informasi Geografis Berbasis Dekstop dan Web, Yogyakarta. Gava Media.

http://dispendukcapil.malangkota.go.id/ diakses pada tanggal 22 Juli 2014 pada pukul 12.49. 